\title{
Reference values of the bioimpedance vector components in a Caribbean population
}

Lexa Nescolarde ${ }^{a}$, , Ana Núñez ${ }^{b}$, Paco Bogónez-Franco ${ }^{a}$, Alcibiades Lara ${ }^{c}$, Guillermo Vaillant $^{\mathrm{d}}$, Ricardo Morales ${ }^{\mathrm{e}}$, Javier Rosell-Ferrer ${ }^{\mathrm{a}}$

\footnotetext{
${ }^{a}$ Department of Electronic Engineering, Technical University of Catalonia, c/ Jordi Girona, 1-3, 08034 Barcelona, Spain

${ }^{b}$ Department of Physiology, Medical School, Ave. Las Américas s/n, 90100 Santiago de Cuba, Cuba ${ }^{c}$ Department of Bioengineering, National Research Centre of Applied Electromagnetism, Universidad de Oriente, Ave Patricio Lumumba s/n, 90500 Santiago de Cuba, Cuba

${ }^{d}$ Paediatric Unit, Northern Children's Hospital, c/ Fomento 8, 90900 Santiago de Cuba, Cuba

"Intensive and Intermediate Care Unit,"Saturnino Lora" University Hospital, Ave. Los Libertadores s/n, 90400 Santiago de Cuba, Cuba
}

\section{SUMMARY}

\section{BACKGROUND \& AIMS}

Application of bioelectrical impedance vector analysis (BIVA) requires comparison of an impedance vector to reference intervals derived from healthy subjects. The aim of this work is to obtain reference nomograms of bioimpedance vectors from healthy subjects living in Santiago de Cuba.

\section{METHODS}

A sample of 4030 healthy people, ages 2-80 y, was measured using a tetra-polar whole-body bioimpedance analyzer at $50 \mathrm{kHz}$. BIVA method uses the 50,75 and $95 \%$ confidence ellipses of reference populations to classify individual and group vectors.

\section{RESULTS}

The $95 \%$ confidence ellipses derived among boys and girls (2-12 y) were similar $(P>0.05)$ with significant gender differences $(P<0.05)$ throughout adulthood. Furthermore, we can observe a progressive decrease in the modulus of the impedance with age with the same phase angle from 13 to $59 \mathrm{y}$. However, in both genders on subjects $>60 \mathrm{y}$ we also observed a phase downfall, possibly due to the reduction of mass and structure, by sarcopenia. 


\section{CONCLUSIONS}

Reference ellipses are provided, distributed in six sets resulting in age separation intervals (not in gender) for children from 2 to $12 \mathrm{y}$; two gender specific reference ellipses for teenagers in the range of $13-16 \mathrm{y}$, for adults from 17 to $59 \mathrm{y}$ and for elderly people from 60 to $80 \mathrm{y}$.

Keywords: Bioimpedance vector analysis, Children, Adults, Ethnicity

\section{INTRODUCTION}

Impedance $(Z)$, represented as a complex number, which consists of real part or resistance $(R)$ and imaginary part or reactance $(\mathrm{Xc})$. Resistance represents the opposition to the flow of an injected alternating current, through intra and extra-cellular ionic solutions; while $\mathrm{Xc}$ represents the dielectric or capacitive component of cell membranes, organelles, and tissue interfaces. ${ }^{1}$ When the $R$ and the $\mathrm{Xc}$ are measured at $50 \mathrm{kHz}$, normalized by the height $(H)$ of the subjects $(R / H$ and $\mathrm{Xc} / H)$ and represented in a $\mathrm{RXc}$-graph through tolerance and confidence ellipses, it is called bioimpedance vector analysis (BIVA) to classify hydration and body cell mass. ${ }^{2}$ An individual vector can then be compared with the reference $50 \%, 75 \%, 95 \%$ tolerance ellipses calculated in the healthy population of a same race (or ethnicity), gender, body mass index (BMI), and age class. ${ }^{3}, \underline{4}, \underline{5}, \underline{6}$ The main advantage of the method is that is unaffected by regression equations adjusted by age or gender, body geometry or hydration state to estimate body composition. BIVA only depends on the reproducibility and accuracy of bioimpedance measurements and intra-individual variability in body composition. ${ }^{?}$

The aim of the present study is to establish bivariate reference intervals for the impedance vector in healthy Cubans aged 2-80 y.

\section{MATERIALS AND METHODS}

\subsection{SAMPLE}

Bioimpedance measurement was done while medical visits to 6008 healthy volunteers living in Santiago de Cuba, during a period of 8 years, from January 2001 to November 2008. Weight $(W)$ and height $(H)$ were measured at the beginning of the bioimpedance study. One thousand nine hundred and seventy eight people $(32.92 \%)$ were excluded because, according to tables from World Health Organization (http://www.who.int), they exceeded the 95th percentile for body mass index (BMI). The final sample included 4030 volunteers aged 2-80 y. Parents of children and adult participants signed informed consent before starting the study. 
The sample was partitioned as children $(2-3,4-5,6-7,8-9,10-11,12$ y), post-puberty (13-16 y), adult (17-59 y) and old age (60-80 y). Adolescence in Cuba occurs around age $13^{\underline{8}}$ reaching maturity at $16 \mathrm{y} .^{-}$

\subsection{ELECTRODE PLACEMENT AND BIOIMPEDANCE ANALYZER}

Bioimpedance parameters were obtained by measuring standard tetra-polar wholebody ${ }^{9}$ configuration with a BioScan: BL-960141 (Biologica, Barcelona, Spain). A $50 \mathrm{kHz}$ frequency was used for the measurements.

Disposable pre-gelled $\mathrm{Ag} / \mathrm{AgCl}$ electrodes model 3M Red Dot 2560 (3M, Ontario, Canada) were used for adults and the 3M 2248-50 Red Dot for the paediatric sample.

\subsection{BODY IMPEDANCE VECTOR ANALYSIS (BIVA). DATA ANALYSIS}

In the BIVA method, the complex electrical bioimpedance vector is normalized by the subject's height $(Z / H, O h m / m)$. The two components of the impedance vector: resistance $(R)$ and reactance $(\mathrm{Xc})$, standardized by height $(H)$, are considered two correlated normal random variables (i.e. a bivariate Gaussian vector) forming elliptical probability regions on the RXc-graph, ${ }^{2}$ which are confidence ellipses for mean vectors and tolerance ellipses for individual vectors.

Three tolerance ellipses are considered in the RXc-graph, the median, the third quartile, and the 95th percentile, that are regions including $50 \%, 75 \%$ and $95 \%$ of individual points, respectively. The 95\% confidence ellipses are plotted in the RXcgraph, for both male and female sample by age group, using BIVA method. Two mean vectors have a significantly different $(P<0.05)$ position in the RXc-graph if their $95 \%$ confidence ellipses are separated according to Hotelling's $T^{2}$ test. $\stackrel{10}{ }$ In case of overlapping are not a significantly different $(P>0.05)$. The two-sample Hotelling's $T^{2}$ test is a multivariate extension of the Student's $t$ test for unpaired data in comparison of mean vectors from two groups.

Previously to obtain the confidence and tolerance ellipses for Cuban sample we made two measures, in a subset of the sample of 30 volunteer between 20 and 35 years using the same electrodes that were used in the study, one after the other, one with BioScan and other one with BIA 101 (Akern-Srl, Florence, Italy) to assess the accuracy of BioScan against the most used analyzer in body composition. Then, we apply a linear regression in the original data obtained from BioScan and BIA 101 $y=0.9861 x-6.9128$ with $R^{2}=0.9958$ in $R$ parameter, while for $\mathrm{Xc}$ we found $y=0.7 x-0.5557$ with $R^{2}=0.7526$. Second, we obtain the corrections factors from this linear regression. Finally, we apply these corrections factors to all the data to obtain $y=x-0.0003$ in $R$ parameter and $y=x-0.00002$ in Xc. It can be 
seen that the biggest difference between the equipment's is a gain error in the reactance estimation of the BioScan.

\section{RESULTS}

Table 1 shows the mean \pm SD of body mass index $(B M I)$, normalized resistance $(R / H)$ and reactance $(\mathrm{Xc} / H)$ by age and gender, as well as the Pearson's correlation coefficient $(r)$ between $R / H$ and $\mathrm{Xc} / H$ and the result of a Hotelling's $T^{2}$ test between male and female of the same age group of the 4030 Cuban reference. Fig. 1 presents the $95 \%$ confidence ellipses by gender among the various age groups and shows the overlap of confidence ellipses $(P>0.05)$ among the boys and girls $(2-12 \mathrm{y})$. The $95 \%$ confidence ellipses differed $(P<0.05)$ by gender among participant groups exceeding $13 \mathrm{y}$ of age (Fig. 2).

Table 1. Bivariate interval by class of age for Cuban sample, phase angle, Pearson coefficient $r(R, \mathrm{Xc})$ and result of Hotelling's $T^{2}$ test.

\begin{tabular}{|c|c|c|c|c|c|c|c|c|c|}
\hline $\begin{array}{l}\text { Age } \\
\text { (y) }\end{array}$ & $\begin{array}{l}\text { Gender, } \\
\text { Male, M } \\
\text { Female, } \\
\text { F }\end{array}$ & $\begin{array}{l}\text { Sample } \\
\text { Size } \\
(n)\end{array}$ & $\begin{array}{l}\text { BMI } \\
\left(\mathrm{kg} / \mathrm{m}^{2}\right) \\
\text { Mean } \\
\text { SD }\end{array}$ & $\begin{array}{l}H \\
(\mathrm{~m})\end{array}$ & $\begin{array}{l}\text { RIH } \\
\text { (Ohm/m) } \\
\text { Mean } \\
\text { SD }\end{array}$ & $\begin{array}{l}\mathrm{Xc} / H \\
(\mathrm{Ohm} / \mathrm{m}) \\
\text { Mean } \\
\text { SD }\end{array}$ & $\begin{array}{l}\text { Phase Angle } \\
\left({ }^{\circ}\right) \\
\text { Mean } \\
\text { SD }\end{array}$ & $\begin{array}{l}r \\
(R, \mathrm{Xc})\end{array}$ & $\begin{array}{l}\text { Hotelling's } T 2 \\
\text { test }\end{array}$ \\
\hline $2-3$ & $\mathrm{M}, \mathrm{F}$ & 61 & $\begin{array}{l}16.2 \\
0.9\end{array}$ & $\begin{array}{l}1.0 \\
0.1\end{array}$ & $\begin{array}{l}741.4 \\
79.2\end{array}$ & $\begin{array}{l}70.9 \\
8.1\end{array}$ & $\begin{array}{l}5.5 \\
0.5\end{array}$ & 0.67 & $(P>0.05)$ \\
\hline $4-5$ & $M, F$ & 91 & $\begin{array}{l}15.9 \\
1.0\end{array}$ & $\begin{array}{l}1.1 \\
0.0\end{array}$ & $\begin{array}{l}651.2 \\
65.6\end{array}$ & $\begin{array}{l}63.2 \\
6.4\end{array}$ & $\begin{array}{l}5.6 \\
0.5\end{array}$ & 0.55 & $(P>0.05)$ \\
\hline $6-7$ & $\mathrm{M}, \mathrm{F}$ & 165 & $\begin{array}{l}15.9 \\
1.0\end{array}$ & $\begin{array}{l}1.2 \\
0.1\end{array}$ & $\begin{array}{l}578.5 \\
52.4\end{array}$ & $\begin{array}{l}57.5 \\
6.3\end{array}$ & $\begin{array}{l}5.7 \\
0.5\end{array}$ & 0.60 & $(P>0.05)$ \\
\hline $8-9$ & $\mathrm{M}, \mathrm{F}$ & 179 & $\begin{array}{l}16.6 \\
1.3\end{array}$ & $\begin{array}{l}1.3 \\
0.1\end{array}$ & $\begin{array}{l}513.0 \\
51.1\end{array}$ & $\begin{array}{l}51.0 \\
5.2\end{array}$ & $\begin{array}{l}5.7 \\
0.4\end{array}$ & 0.67 & $(P>0.05)$ \\
\hline $10-11$ & $\mathrm{M}, \mathrm{F}$ & 196 & $\begin{array}{l}17.6 \\
1.8\end{array}$ & $\begin{array}{l}1.4 \\
0.1\end{array}$ & $\begin{array}{l}461.3 \\
59.6\end{array}$ & $\begin{array}{l}47.0 \\
5.9\end{array}$ & $\begin{array}{l}5.8 \\
0.6\end{array}$ & 0.59 & $(P>0.05)$ \\
\hline 12 & $\mathrm{M}, \mathrm{F}$ & 109 & $\begin{array}{l}19.0 \\
1.9\end{array}$ & $\begin{array}{l}1.5 \\
0.1\end{array}$ & $\begin{array}{l}419.6 \\
50.8\end{array}$ & $\begin{array}{l}43.6 \\
5.0\end{array}$ & $\begin{array}{l}5.9 \\
0.5\end{array}$ & 0.71 & $(P>0.05)$ \\
\hline $13-16$ & M & 101 & $\begin{array}{l}19.5 \\
2.0\end{array}$ & $\begin{array}{l}1.6 \\
0.1\end{array}$ & $\begin{array}{l}335.2 \\
48.7\end{array}$ & $\begin{array}{l}37.0 \\
4.9\end{array}$ & $\begin{array}{l}6.3 \\
0.5\end{array}$ & 0.71 & $(P<0.05)$ \\
\hline & $\mathrm{F}$ & 161 & $\begin{array}{l}20.4 \\
2.0\end{array}$ & $\begin{array}{l}1.6 \\
0.1\end{array}$ & $\begin{array}{l}413.0 \\
45.8\end{array}$ & $\begin{array}{l}43.6 \\
4.7\end{array}$ & $\begin{array}{l}6.1 \\
0.5\end{array}$ & 0.69 & \\
\hline $17-59$ & M & 1263 & $\begin{array}{l}23.5 \\
2.2\end{array}$ & $\begin{array}{l}1.7 \\
0.1\end{array}$ & $\begin{array}{l}292.3 \\
32.4\end{array}$ & $\begin{array}{l}33.8 \\
3.6\end{array}$ & $\begin{array}{l}6.6 \\
0.5\end{array}$ & 0.72 & $(P<0.05)$ \\
\hline & $\mathrm{F}$ & 1399 & $\begin{array}{l}22.8 \\
2.2\end{array}$ & $\begin{array}{l}1.6 \\
0.1\end{array}$ & $\begin{array}{l}398.0 \\
46.8\end{array}$ & $\begin{array}{l}42.0 \\
5.2\end{array}$ & $\begin{array}{l}6.0 \\
0.5\end{array}$ & 0.71 & \\
\hline $60-80$ & M & 174 & $\begin{array}{l}23.1 \\
2.1\end{array}$ & $\begin{array}{l}1.7 \\
0.1\end{array}$ & $\begin{array}{l}318.2 \\
42.2\end{array}$ & $\begin{array}{l}32.0 \\
4.1\end{array}$ & $\begin{array}{l}5.8 \\
0.6\end{array}$ & 0.64 & $(P<0.05)$ \\
\hline & $\mathrm{F}$ & 128 & $\begin{array}{l}23.6 \\
2.4\end{array}$ & $\begin{array}{l}1.6 \\
0.1\end{array}$ & $\begin{array}{l}404.4 \\
59.6\end{array}$ & $\begin{array}{l}38.0 \\
5.4\end{array}$ & $\begin{array}{l}5.4 \\
0.5\end{array}$ & 0.72 & \\
\hline
\end{tabular}




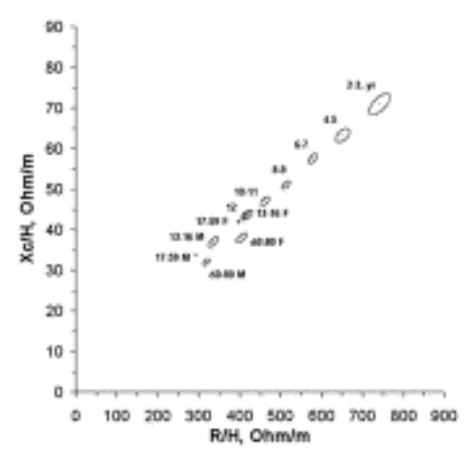

Fig. 1 The 95\% confidence ellipses from Cuban sample: Hotelling's $T^{2}$ test results.

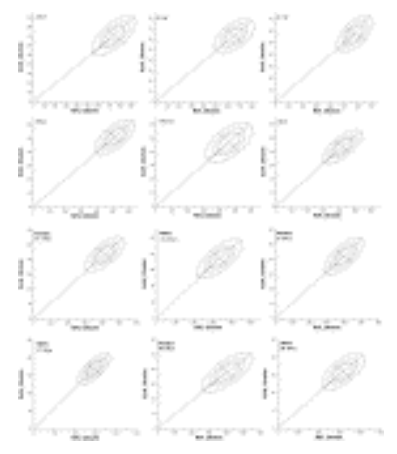

Fig. 2 The 50\%, 75\% and 95\% tolerance ellipse for Cuban healthy sample between 2 and $80 \mathrm{y}$.

\section{DISCUSSION}

Many healthy populations, of diverse race-ethnicities, have been characterized by BIVA. $\underline{4}, \underline{5}$ The confidence ellipses of different ethnic groups, stratified by gender, did not overlap and the mean vectors were significantly different $(P<0.05)$ by Hotelling's $t$ test. The Cuban population is characterized by a mixture of several race-ethnicities such as Caucasian, black, half-caste and intercultural influences from Spanish, French, Chinese and black African. In the study by Nescolarde et al. 2004, 11 the $95 \%$ confidence ellipses were drawn for mean vectors of different races (Caucasian, black, half-caste) from an adult Cuban healthy sample. Following a parsimony criterion, different tolerance intervals should be drawn for different populations only if the $95 \%$ confidence intervals (ellipses) of different race-ethnicities do not overlap $(P<0.05)$ using the Hotelling's test for difference in mean vector position in the R-Xc graph. ${ }^{4}$ Due to the close distribution of mean vectors with overlap in the $95 \%$ confidence ellipses, that was found for the three race-ethnicities, only one set of sex-specific tolerance ellipses (50\%, 75\%, and 95\%) was used in Nescolarde et al. 2004, 11 and for this reason we did not separate by race-ethnicity the people in the present study. 
According to the results of Hotelling's $T^{2}$ test by confidence ellipses (Fig. 1), the reference interval for bioimpedance components by class of age $(\mathrm{y})$ to be used in practice is: childhood $(2-3,4-5,6-7,8-9,10-11,12)$, puberty (13-16), adult (17-59) and old age (60-80). This is shown through $50 \%, 75 \%$, and $95 \%$ tolerance ellipses for Cuban sample in Fig. 2. Confirming the information of the Cuban health system, in our sample adolescence occurs around age $13 y^{\underline{8}}$ so here begins the differences by gender in body composition and bioelectrical parameters $R$ and $\mathrm{Xc}$, similar to the results obtained by De Palo et al. (2000).

Recall that in the RXc-graph the resistance parameter $(R / H)$ provides information on the hydration state of soft tissues while the reactance parameter $(\mathrm{Xc} / H)$ provides information on the structure. ${ }^{2}$ The phase angle decreases with increasing age, due to a reduction in reactance due to loss of muscle mass and an increase in resistance due to the declining proportion of body water at the expense of increasing fat mass. $\stackrel{12}{\text { In }} \underline{\text { Fig. } 1}$ we can observe a progressive decrease in the modulus of the impedance (vector length) with age with same phase angle from 13 to $59 \mathrm{y}$. However, in both genders on subjects $>60 \mathrm{y}$ we also observed a phase downfall possibly due to the reduction of mass and structure, by sarcopenia.

One limitation to compare the results obtained with bioimpedance measurement in different populations is the variety of bioimpedance analyzers that exist in the market that have different specifications. It would be necessary to standardize the specifications and a test method to evaluate the accuracy of these systems. For example, it is already accepted that a phase-sensitive detection method has to be used to avoid significant errors of up to $10 \Omega$ for $R$ and $10-12 \Omega$ for $\mathrm{Xc}^{\underline{13}}, \underline{7}$ that have a negative impact on assessment of hydration status. ${ }^{?}$

\section{CONCLUSION}

For the healthy Cuban population, characterized by a mixture of several raceethnicities and intercultural influences, we propose to use reference ellipses for six intervals of children 2-12 y, two gender specific reference ellipses for teenagers from 13 to 16 y range, two gender specific reference ellipses for adults (17-59 y) and two gender specific reference ellipses for elders (60-80 y).

\section{FUNDING}

No funding source.

\section{STATEMENT OF AUTHORSHIP}

Authors' responsibilities were as follows: AN, AL: literature research, human measure; LN, PBF: literature research, statistical analysis and manuscript writing; GV, RM and JRF critical input and manuscript revision. 


\section{CONFLICT OF INTEREST}

Authors declare not having any financial conflict of interest.

\section{ACKNOWLEDGEMENT}

Authors are very grateful to thank Professor Antonio Piccoli from the Department of Medical and Surgical Science, University of Padua, Italy for his valuable scientific advice in BIVA methods.

\section{REFERENCES}

1. Kushner RF. Bioelectrical impedance analysis: a review of principles and applications. J Am Coll Nutr. 1992;11:199-209

2. Piccoli $A$, Rossi B, Pillon $L$, Bucciante $G$. A new method for monitoring body fluid variation by bioimpedance analysis: the RXc graph. Kidney Int. 1994;46:534-539

3. De Palo T, Messina G, Edefonti A, Perfumo F, Pisanello L, Peruzzi L, et al. Normal values of the bioelectrical impedance vector in childhood and puberty. Nutrition. 2000;16:417-424

4. Ward LD, Heitman BL, Craig P, Stroud D, Azinge EC, Jebb S. Association between ethnicity, body mass index, and bioelectrical impedance. Ann $N$ Y Acad Sci. 2001;258:199-202

5. Piccoli A, Pillon L, Dumler F. Impedance vector distribution by sex, race, body mass index, and age in the United States: standard reference intervals as bivariate $Z$ scores. Nutrition. 2002;18:156-170

6. Bosy-Westphal A, Danielzik S, Dörhöfer R-P, Piccoli A, Müller MJ. Patterns of bioelectrical impedance vector distribution by body mass index and age: implications for body-composition analysis. Am J Clin Nutr. 2005;82:60-68

7. Lukaski HC, Piccoli A. Bioelectrical impedance vector analysis for assessment of hydration in physiological states and clinical conditions. In: Preedy $\mathrm{V}$ editors. Handbook of anthropometry. London, UK: Springer; 2012;p. 287-315

8. Castellanous B, Gonzalez A. Sex education and the problem of early sexual relations among adolescents. Bol Psicol. 1981;4(3):44-58

9. Lukaski HC, Bolonchuck WW, Hall CB, Siders WA. Validation of tetrapolar bioelectrical impedance method to assess human body composition. J Appl Physiol. 1986;60:1327-1332

10. Hotelling $\mathrm{H}$. The generalization of Student's ratio. Ann Math Statist. 1931;2(3):360378

11. Nescolarde L, Rosell J, Piccoli A, Morales R, Román A, Núñez A, et al. Influence of race on impedance vector position in the R-Xc plane. In: Proceedings of the XIlth international conference on electrical bioimpedance: 2004 Jun 20-24. Gdansk (Poland): University of Gdansk; 2004;p. P329-P332

12. Norman K, Stobäus N, Pirlich M, Bosy-Westphal A. Bioelectrical phase angle and impedance vector analysis - clinical relevance and applicability of impedance parameters. Clin Nutr. 2012;31:854-861

13. Chumlea WC, Guo SS, Kuczmarski RJ, Flegal KM, Johnson CL, Heymsfield SB, et al. Body composition estimates from NHANES III bioelectrical impedance data. Int J Obes. 2002;26:1596-1609 